\title{
Comparison of spinal block characteristics on height and weight based dosage versus fixed dosage of intrathecal bupivacaine for elective caesarean section
}

\author{
A Nagraj', P Gupta ${ }^{2 *}$ A Sahni ${ }^{3}$ \\ Senior Resident ${ }^{l}$, Department of Anaesthesia \& Intensive care, All India Institute of Medical \\ Science, New Delhi 110029, India. Professor ${ }^{2 *}$, Consultant \& Professor ${ }^{3}$, Department of \\ Anaesthesia \& Intensive care, Safdarjang Hospital \& Vardhman Mahavir medical college, \\ New Delhi 110034, India.
}

\begin{abstract}
Spinal anaesthesia is a standard procedure for the conduct of elective and emergency caesarean section. Spinal block induced sympathetic blockade is often associated with incidence of maternal hypotension. Various measures to limit sympathetic blockade has been documented. This prospective double-blind study evaluated the spinal block achieved with height and weight adjusted dose versus fixed dose of bupivacaine with fentanyl.
\end{abstract}

Keywords: Caesarean section; patient body weight; patient body height; local anaesthetic

\section{Introduction}

Spinal anaesthesia is the preferred choice of anaesthesia for the conduct of emergency and elective cesarean section in obstetric parturients owing to the associated physiological changes during pregnancy. Hypotension during spinal anaesthesia for caesarean section continues to be a major problem. Maternal hypotension may be associated with distressing unpleasant symptoms like dizziness, nausea, vomiting. In severe cases, hypotension can result in unconsciousness, apnoea, and cardiac arrest in parturients and may also impair placental perfusion and compromise foetal outcome. ${ }^{1}$

Left uterine displacement, leg elevation, preloading / co-loading with intravenous fluids, prophylactic administration of vasopressors, are some of the frequently employed strategies to prevent hypotension. ${ }^{2,3,4}$ Others such as use of lower doses of local anaesthetic agents, use of additives like opioids, clonidine and rate and site sympathetic blockade and thus reduces the haemodynamic changes. ${ }^{6}$

The purpose of this study was to evaluate the onset and level of block achieved with height and

\footnotetext{
*Correspondence: P Gupta

E mail: p.gupta182@gmail.com

iD https://orcid.org/0000-0002-3075-3412

Received: $15 / 05 / 2017$

Accepted: 04/07/2017

DOI: http://doi.org/10.4038/slja.v26i1.8238
}

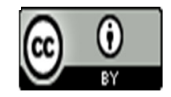

weight based dose versus fixed dose of bupivacaine with fentanyl in parturients scheduled for elective caesarean section and to determine the optimum dose for adequate anaesthesia with minimal side effects.

\section{Material and methods}

Approval was obtained from Ethics Review Committee of Safdarjung Hospital and Vardhman Mahavir Medical College. Study was conducted in Department of Anaesthesia from June 2012 to December 2015. Two hundred patients with singleton pregnancy of American Society of Anaesthesiologists physical status classification I and II, scheduled for elective caesarean section under spinal anaesthesia were included in this double-blind study. Patients with pre -existing hypertension or pregnancy -induced hypertension and any contraindication or refusal for spinal anaesthesia were excluded.

The patients were divided randomly into two groups, using a computer-generated random number chart. The patients were not aware of the group that they were in and the observer was blinded too, as the bupivacaine was injected by an independent anaesthesiologist giving the spinal block.

1) Fixed Dose group (FD group) received intrathecal injection of $2 \mathrm{ml}$ of $0.5 \%$ hyperbaric bupivacaine $(10 \mathrm{mg})+0.2 \mathrm{ml}$ of fentanyl (10mcg).

2) Adjusted Dose group (AD Group) received height and weight based doses (Harten's

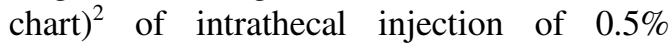
hyperbaric bupivacaine $+0.2 \mathrm{ml}$ of fentanyl (10 mcg). 
Table 1: Doses adjusted to height and weight (Harten's Chart) ${ }^{2}$

\begin{tabular}{|l|l|l|l|l|l|l|l|l|l|}
\hline $\begin{array}{l}\text { Patien } \\
\mathrm{t} \\
\text { weight }\end{array}$ & \multicolumn{7}{|l|}{ Patient height $(\mathrm{cm})$} \\
\cline { 2 - 10 } & $\begin{array}{l}14 \\
0\end{array}$ & $\begin{array}{l}14 \\
5\end{array}$ & $\begin{array}{l}15 \\
0\end{array}$ & $\begin{array}{l}16 \\
0\end{array}$ & $\begin{array}{l}16 \\
5\end{array}$ & $\begin{array}{l}17 \\
0\end{array}$ & $\begin{array}{l}17 \\
5\end{array}$ & $\begin{array}{l}18 \\
0\end{array}$ \\
\hline 50 & 1.5 & 1.7 & 1.8 & 1.9 & & & & & \\
\hline 55 & 1.5 & 1.6 & 1.8 & 1.9 & 2.0 & & & & \\
\hline 60 & 1.4 & 1.6 & 1.7 & 1.8 & 2.0 & 2.1 & & & \\
\hline 65 & 1.4 & 1.5 & 1.7 & 1.8 & 1.9 & 2.1 & 2.2 & & \\
\hline 70 & 1.3 & 1.5 & 1.6 & 1.8 & 1.9 & 2.0 & 2.2 & 2.3 & \\
\hline 75 & & 1.4 & 1.6 & 1.7 & 1.9 & 2.0 & 2.1 & 2.3 & 2.4 \\
\hline 80 & & 1.4 & 1.5 & 1.7 & 1.8 & 2.0 & 2.1 & 2.2 & 2.4 \\
\hline 85 & & & 1.5 & 1.6 & 1.8 & 1.9 & 2.1 & 2.2 & 2.3 \\
\hline 90 & & & 1.4 & 1.6 & 1.7 & 1.9 & 2.0 & 2.2 & 2.3 \\
\hline 95 & & & & 1.5 & 1.7 & 1.8 & 2.0 & 2.1 & 2.3 \\
\hline 100 & & & & 1.5 & 1.7 & 1.8 & 1.9 & 2.1 & 2.2 \\
\hline 105 & & & & & 1.6 & 1.7 & 1.9 & 2.0 & 2.2 \\
\hline 110 & & & & & & 1.7 & 1.8 & 2.0 & 2.2 \\
\hline
\end{tabular}

All the patients were given ranitidine $150 \mathrm{mg}$ orally on the night before surgery. In the operation theatre, intravenous access was secured with an $18 \mathrm{G}$ cannula and co-loaded with Ringer's lactate at $10 \mathrm{ml} / \mathrm{kg}$ over 15 minutes. Ranitidine $50 \mathrm{mg}$ and metoclopramide $10 \mathrm{mg}$ were added to the intravenous fluid. Oxygen was administered at a flow rate of $6 \mathrm{~L}$ per minute through a venti mask. $\left(\mathrm{FiO}_{2} 40 \%\right)$. Perioperatively, heart rate (HR), electrocardiograph (ECG), systolic blood pressure (SBP), and oxygen saturation $\left(\mathrm{SpO}_{2}\right)$ were continuously monitored.

Under aseptic precautions, subarachnoid block was performed in the left lateral decubitus position using 25G Quincke's spinal needle at L2-3, or L3,4 vertebral interspace. After confirming free flow of clear CSF, the study drug i.e. fixed or adjusted dose was injected at a rate of $0.2 \mathrm{ml} /$ second. Patients were placed supine immediately, giving a left lateral tilt with a wedge beneath the right pelvis.

Sensory block was assessed by loss of sensation to pin prick with $22 \mathrm{G}$ hypodermic needle and loss of cold sensation to spirit swab, along the midclavicular line bilaterally every $2 \mathrm{mins}$ for next 20 mins till two consecutive readings of sensory block level remained the same (i.e. when highest cephalad spread of sensory block has occurred), after which the highest level was assessed at every ten minutes interval till the end of surgery. The skin incision was allowed when the target of spinal block reached to the thoracic dermatome (T5) level.
Time for onset of, time to sensory blockade to regress two segments, quality of sensory and motor block was noted.

If desired level was not achieved within 10mins, $10^{0}$ head down tilt was given to improve block height. If discomfort persisted, boluses of ketamine $(0.5 \mathrm{mg} / \mathrm{kg})$ were administered. If these measures failed, general anaesthesia was administered.

Hypotension was treated when systolic blood pressure fell below $90 \mathrm{mmHg}$ or $20 \%$ below the baseline value (whichever was lower) with ephedrine 5mg i.v. bolus. Bradycardia was treated when the heart rate fell below 50/min, with i.v. atropine sulphate $0.6 \mathrm{mg}$ bolus.

At the end of surgery, quality of block was assessed from surgeon and quality of intra operative analgesia was assessed by patient's satisfaction on two-point scale. (adequate/ inadequate)

Neonatal assessment was done using APGAR score at 1 and 5mins. Fetal $\mathrm{pH}$ and Base Excess (BE) indices were also measured by uterine blood gas analysis for neonatal assessment.

\section{Statistical analysis}

Assuming the difference of mean level of block between the two groups as $20 \%$ and an alpha error of 0.05 with power of $80 \%$, minimum sample size required was 100 in each group. Descriptive statistical methods like mean, standard deviation and frequency distributions were calculated for continuous and categorical variables respectively. Analysis of all continuous quantitative variables like blood pressure, pulse rate, time for peak sensory block, time for peak motor block etc. were compared using unpaired student's $t$ test and nonparametric Wilcoxon Mann -Whitney $U$ test.

For qualitative variables/ categorical variables/ group demographic data Chi-square test or Fisher's -exact test was used. P value $<0.05$ was considered statistically significant.

\section{Results}

A total of two hundred parturients with 101 parturients in adjusted dose group (Group AD) and 99 parturients in fixed group (Group FD) were analysed.

The demographic profile of parturients in both the groups were comparable with respect to age 
$(\mathrm{p}$ value $=0.866)$, weight $(\mathrm{p}$ value $=0.653)$ and height $(\mathrm{p}$ value $=0.138)$ and gestational age $(\mathrm{p}=0.346)$. $($ Table 2$)$.

Table 2: Patient demographic data

\begin{tabular}{|l|l|l|l|}
\hline & Group AD & Group FD & P value \\
\hline Age $(\mathrm{yr})$ & $25.22 \pm 3.65$ & $24.97 \pm 3.33$ & 0.866 \\
\hline Weight $(\mathrm{kg})$ & $60.84 \pm 9.65$ & $59.62 \pm 7.82$ & 0.653 \\
\hline Height $(\mathrm{cm})$ & $154.22 \pm 6.67$ & $155.60 \pm 6.42$ & 0.138 \\
\hline $\begin{array}{l}\text { Gestational age } \\
\text { (wks) }\end{array}$ & $38.65 \pm 1.445$ & $38.85 \pm 1.473$ & 0.346 \\
\hline
\end{tabular}

Values are mean \pm standard deviation

On dose adjustment for height and weight, a significantly lower mean dose of intrathecal bupivacaine was $9 \pm 0.5 \mathrm{mg}(8.5-9.5 \mathrm{mg})$ given than that of $10 \mathrm{mg}$ in fixed dose group $(\mathrm{p}=0.005)$ (Table 3).

Table 3: Bupivacaine dose, spinal block characteristics.

\begin{tabular}{|c|c|c|c|}
\hline & $\begin{array}{l}\text { FIXED } \\
\text { GROUP } \\
(n=99)\end{array}$ & $\begin{array}{l}\text { ADJUSTED } \\
\text { GROUP } \\
(\mathrm{n}=101)\end{array}$ & $P$ value \\
\hline $\begin{array}{l}\text { Bupivacaine dose } \\
\text { (mgs) }\end{array}$ & 10 & $9 \pm 0.5(8.5-9.5)$ & $p=0.000$ \\
\hline $\begin{array}{l}\text { Maximum } \\
\text { [median] cephalad } \\
\text { spread }\end{array}$ & T3 [T1-T5] & T4[T4-T5] & \\
\hline T3 dermatome & $20(19.8 \%)$ & $10(13.13 \%)$ & $p=0.001$ \\
\hline T2 & $11(10.89 \%)$ & $2(2.1)$ & \\
\hline $\mathrm{T1}$ & $5(4.95 \%)$ & 0 & $p=0.000$ \\
\hline $\begin{array}{l}\text { Quality of } \\
\text { intraoperative } \\
\text { anaesthesia } \\
\text { Excellent } \\
\text { Good }\end{array}$ & $\begin{array}{l}97 \\
2\end{array}$ & $\begin{array}{l}101 \\
0\end{array}$ & $p=0.244$ \\
\hline $\begin{array}{l}\text { Supplementary } \\
\text { analgesia }\end{array}$ & $2(1.98 \%)$ & 0 & \\
\hline Head down tilt & $3(3 \%)$ & 0 & \\
\hline $\begin{array}{l}\text { Ephedrine used } \\
\text { (mg) }\end{array}$ & $9.65[3-16.8]$ & $7[0-10]$ & $p=0.008$ \\
\hline
\end{tabular}

Values are median or number (percentage)

Though the time to attain target sensory block to dermatome level T5 ( $\mathrm{p}$ value $=0.810$ ) was comparable in both the groups, the maximum level of sensory block was extended up to T1 dermatome $(4.95 \%)$ in fixed dose group while in parturients in adjusted dose group, block did not exceed beyond T3(Figure1). No parturients in Group AD, had a sensory level reaching to T1.
Figure 1: Comparison of maximum level of sensory block.

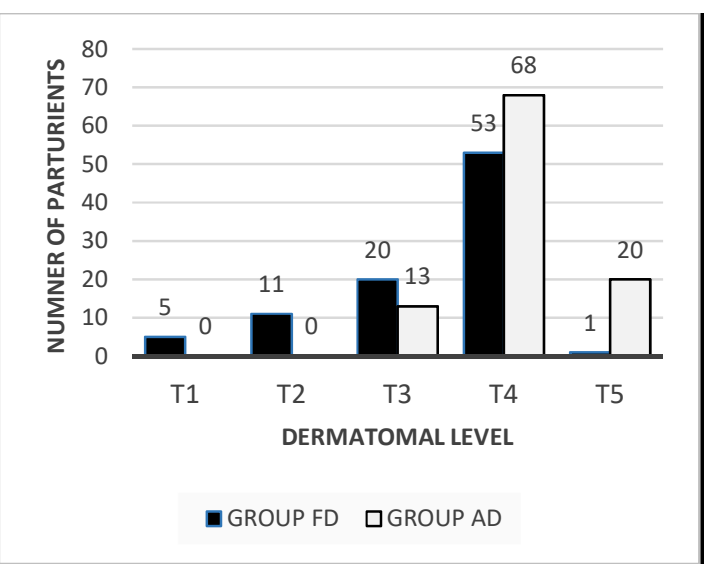

All the parturients in both groups achieved complete motor blockade in our study. Time to achieve maximum motor block (Mmax) was also comparable in both the groups ( $\mathrm{p}$ value $=0.594)$. All the parturients in both groups achieved complete motor block.

Quality of sensory block was assessed on Gormely and Hill scoring system. ${ }^{8}$ In group AD 97 parturients had a score of 2 (no sensation) as compared to group $\mathrm{AD}$ where all parturients $(100 \%)$ had a score of 2 . Two parturients in group FD had blunted sensation (score1). There was no significant difference between the groups in the quality of motor block $(\mathrm{p}=0.357)$ and sensory block ( $\mathrm{p}$-value $=0.244)$.

The intraoperative pain was assessed on visual analogue score where 0 represented no pain and 10 represented maximum or unbearable pain. All the patients in height and weight adjusted dose group $(n=101)$ and majority of patients $(n=99)$ in fixed dose group had excellent intraoperative analgesia. Two patients in fixed dose group required supplemental analgesia with ketamine. However, none of the patients in either group required conversion to general anaesthesia.

$\underline{\text { Side-Effects }}$

A significantly $(\mathrm{p}=.001)$ large number of parturients $(43 \%)$ in fixed dose group had hypotension as compared to $20 \%$ in height and weight adjusted dose group. The minimum recorded SBP in fixed dose group (Group FD) was $102 \pm 13 \mathrm{mmHg}$ as compared to $106.9 \pm$ $6.9 \mathrm{mmHg}$ in adjusted dose group. The following 
figure shows the trend of mean systolic BP between the two groups (Figure 2).

Figure 2: Trend of systolic blood pressure

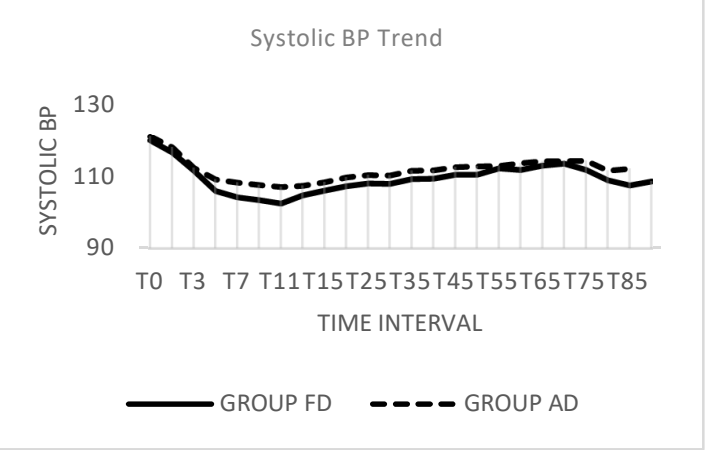

Incidence of episodes of hypotension (10 in group FD, 2 in Group AD) was higher in fixed group with $75 \%$ (9 parturients) having sensory block of T3 or above. Also, a higher median dose of ephedrine was used in group FD. (9.65 mg vs $7 \mathrm{mg}$; $\mathrm{p}$ value $=0.018$ )

In our study, the incidence of nausea $(\mathrm{p}=0.048)$ and shivering was more in Group FD (25\% vs $9 \%$ ) with a significant statistical difference (p value $=0.002$ ). None of the parturients in our study had pruritus or respiratory depression in either group. (Figure 3)

Figure 3: Comparison of complications between the groups

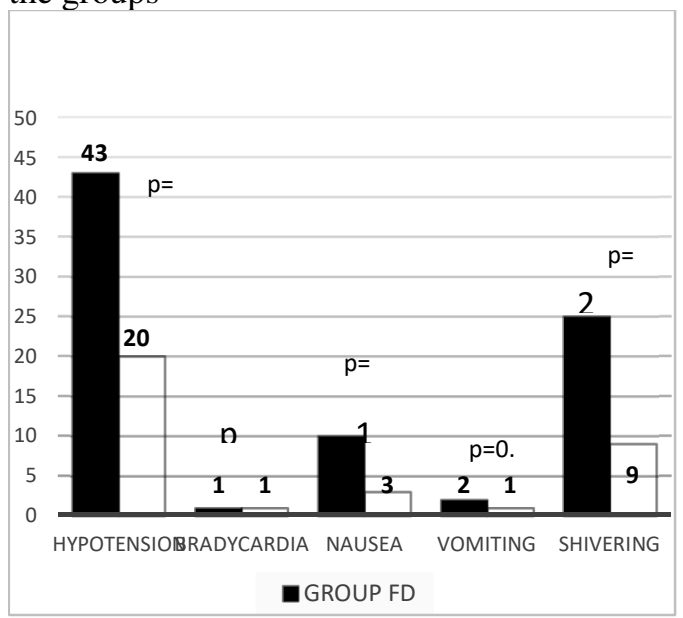

Apgar scores at $1(\mathrm{p}$ value $=0.394)$ and $5(\mathrm{p}$ value $=0.390$ ) minutes after delivery were comparable in both groups. The cord blood $\mathrm{pH}$ of all the neonates were above $>7.2$ and were comparable in both groups. Only one neonate from fixed dose group had base deficit of 12 and rest of the babies had a base deficit less than 12. This was statistically insignificant. $(p=0.49)$

\section{Discussion}

Main side effect of spinal anaesthesia is hypotension occurring as a result of sympathetic blockade. Variables like baricity, total dose, type of local anaesthetic solution, injection site, patient positioning and parturient characteristics (age, height, weight) have been documented to influence the level of regional anaesthesia. ${ }^{9}, 10,11,12$ In this prospective, double-blind, randomized study, we compared spinal block characteristics following two intrathecal dosing regimens for cesarean section under spinal anaesthesia based on either patient height plus weight adjusted or fixed dose.

Thoracic block to dermatome $\mathrm{T}_{5}$ for loss of pinprick sensation has been accepted for caesarean section, so a dermatome $\mathrm{T}_{5}$ block was targeted before allowing surgery in our study. ${ }^{13,14}$

There was no statistically significant difference between the two groups in the onset of spinal anaesthesia to target level of $T_{5}$. However, the incidence of hypotension and the requirement of vasoconstrictor (ephedrine) was less in the doseadjusted group than in the fixed dose group.

Study by Harten et $\mathrm{al}^{2}$ and Subedi $\mathrm{A}$ et $\mathrm{al}^{13}$ reported a delayed onset time to target level of $\mathrm{T}_{5}$ in adjusted dose as compared to fixed dose may be because of use of higher doses of bupivacaine in their study in the fixed dose group. In our study, the maximum level of sensory block (T1) attained was higher in fixed dose group and was comparable to Subedi A et al.

Both, Harten et al and Subedi A et al reported decreased incidence and severity of maternal hypotension after adjusting the dose of hyperbaric bupivacaine to the patient's height and weight, which was comparable with our study.

The incidence of nausea ( $\mathrm{p}-0.0483)$ and shivering ( $\mathrm{p}=0.002$ ) was higher in FD group as compared to $\mathrm{AD}$ group in our study. Similar findings were shown by Harten et al and Subedi et al.

Severe maternal hypotension may contribute to umbilical acidosis. Hence cord blood acid base analysis was done. In similar studies based on decreased bupivacaine dose according to height and /or weight, none have analysed umbilical cord blood gases. Fetal acidosis will be present when $\mathrm{pH}$ is less than 7.2 with base deficit of more than 12. In our study, cord blood $\mathrm{pH}$ and base 
deficit of all neonates was comparable in both groups. Neonatal outcome was good and similar to other studies.

The main finding of our study was that on adjustment of intrathecal dose of heavy bupivacaine on the basis of the height and weight of parturient (Harten's chart) significantly reduced amount of bupivacaine used for caesarean section. The relatively lower dose of bupivacaine used in the adjusted group restricted spinal block segments and the extent of sympathetic block thus improving the safety margin of haemodynamic effects seen after spinal anaesthesia. Other studies have also reported better haemodynamic stability after a dose adjustment of heavy bupivacaine according to the height and weight of patients. ${ }^{13,14}$

\section{Conclusion}

Thus, we conclude that hyperbaric bupivacaine (0. 5\%) dosing regimen based on patient height and weight with $10 \mu \mathrm{g}$ fentanyl achieved adequate anaesthesia for cesarean sections while minimizing the untoward side effects of maternal hypotension with reduced use of vasopressors and good fetal outcome.

Clinical trial registry: CTRI/2017/04/0083

\section{References}

1. Corke BC, Datta S, Ostheimer GW, Weiss JB, Alper MH. Spinal anaesthesia for caesarean section. The influence of hypotension on neonatal outcome. Anaesthesia 1982; 37: 658-662. https://doi.org/10.1111/j.13652044.1982.tb01278.x

PMid:7091625

2. Harten J M, Boyne I, Hannah P, Varveris D, Brown A. Effects of a height and weight adjusted dose of local anaesthetic for spinal anaesthesia for elective Caesarean section. Anaesthesia 2005; 60: $348-53$ https://doi.org/10.1111/j.13652044.2005.04113.x PMid: 15766337

3. Kundra P, Khanna S, Habeebullah S, Ravishankar M. Manual displacement of the uterus during Caesarean section. Anaesthesia. 2007;62(5):4605.

https://doi.org/10.1111/j.13652044.2007.05025.x

PMid: 17448057

4. Rout CC, Rocke DA, Gouws E. Leg elevation and wrapping in the prevention of hypotension following spinal anaesthesia for elective caesarean section. Anaesthesia. 1993;48:304-308. https://doi.org/10.1111/j.1365- 2044.1993.tb06948.x

PMid:8494130

5. Mercier FJ, Augè M, Hoffmann C, Fischer C, Le Gouez A. Maternal hypotension during spinal anesthesia for caesarean delivery. Minerva Anestesiol.2013;79(1):62-73.

PMid:23135692

6. Mebazaa MS, Ouerghi S, Ben Meftah R, et al. Reduction of bupivacaine dose in spinal anaesthesia for caesarean section may improve maternal satisfaction by reducing incidence of low blood pressure episodes. Middle East $\mathbf{J}$ Anesthesiol.2010;20(5):673-8. PMid:20803855

7. Hallworth SP, Fernando R, Columb MO, Stocks GM. The effect of posture and baricity on the spread of intrathecal bupivacaine for elective cesarean delivery. AnesthAnalg. 2005;100(4):1159-65.

https://doi.org/10.1213/01.ANE.0000149548.880 29.A2

PMid: 15781538

8. Gormley WF, Hill DA, Murray JM, Fee JP. The effect of the alkalinisation of lignocaine on axillary plexus anaesthesia. Anaesthesia 1996;51(2):185-8.

https://doi.org/10.1111/j.1365-

2044.1996.tb07712.x

PMid:8779380

9. Choi DH, Ahn HJ, Kim MH. Bupivacaine-sparing effect of fentanyl in spinal anesthesia for cesarean delivery. Reg Anesth Pain Med. 2000;25(3):2405. PMid:10834777

10. Bouchnak M, Belhadj N, Chaaoua T et al. Spinal anaesthesia for Caesarean section: dose injection speed have an effect on the incidence of hypotension? Ann Fr AnesthReanim. 2006;25(1):17-9.

https://doi.org/10.1016/j.annfar.2005.07.078 PMid:16226864

11. Bogra J, Arora N, Srivastava P. Synergistic effect of Intrathecal fentanyl and bupivacaine in spinal anesthesia for caesarean section. BMC Anaesthesiology2005;5:5

https://doi.org/10.1186/1471-2253-5-5 PMid:15904498 PMCid:PMC1159169

12. Greene NM. Distribution of local anesthetic solutions within the subarachnoid space. AnesthAnalg1985;64:715. https://doi.org/10.1213/00000539-198507000$\underline{00012}$

PMid:3893222

13. Subedi A, Tripathi M, Bhattarai BK, Gupta PK et al. The effect of height and weight adjusted dose of intrathecal hyperbaric bupivacaine for elective caesarean section. J Nepal Med Assoc 2011; 51(181): 1-6. PMid:22335087 